\title{
Reproductive phases of Miocene algae from central Paratethys and their bearing on systematics
}

\author{
Juraj Hrabovský \\ Acta Palaeontologica Polonica 64 (2), 2019: 417-439 doi:https://doi.org/10.4202/app.00579.2018
}

Coralline algae were widespread in shallow-water environments during the middle Miocene in the central Paratethys. Their distribution and diversity patterns are useful in paleoenvironmental and paleoclimatic studies providing that species identifications are accurate and robust. Taxonomy of fossil coralline algae was traditionally based on morphology of bi/tetrasporophytes whereas taxonomy of extant species is additionally supported by characters that can be observed in the remaining life cycle phases.

Therefore, investigations of such characters in fossil record are also essential to avoid misidentifications of ancient coralline algae. Here, I analyse morphology of reproductive phases in subfamilies Hydrolithoideae and Mastophoroideae from the middle Miocene of the central Paratethys. Analyses of published and newly collected hydrolithoid and mastophoroid coralline algae allow: (i) identification of three species of the genus Hydrolithon and two species of the genus Lithoporella; (ii) description of complete life cycle phases for extinct Hydrolithon lemoinei, H. corculumis, and Hydrolithon sp. 1 and (iii) description of incomplete life cycles for Lithoporella minus and Lithoporella sp. 1. The results also prove that characters associated with trichocytes can be used in some fossil coralline algae, and bi/tetrasporic pore canal anatomy is reliable diagnostic character also for fossil species, as it is used in extant coralline algae of the order Corallinales.

Key words: Corallinales, Hydrolithon, Lithoporella, reproductive phases, Miocene, central Paratethys, Slovakia, Romania.

Juraj Hrabovský [geoljuhr@savba.sk], Earth Science Institute of the Slovak Academy of Sciences, Dúbravská cesta 9, 84005 Bratislava, Slovakia.

This is an open-access article distributed under the terms of the Creative Commons Attribution License (for details please see creativecommons.org), which permits unrestricted use, 
distribution, and reproduction in any medium, provided the original author and source are credited.

FoF Full text $(1,689.6 \mathrm{kB})$ ।

Far Supplementary file $(631.0 \mathrm{kB})$ 